\title{
Evaluation of an interactive learning environment: theory and practice
}

\author{
M R de Villiers \\ University of South Africa
}

\begin{abstract}
This article is a follow-up to "Instructional theories of experts: a practical implementation" in SAJHE Volume 12(2) of 1998 by the same author. The previous article discussed current instructional and learning theories and tenets of instructional design, upon which a prototype computerised interactive learning and practice environment has been developed for first-level university students in theoretical computer science. The environment gives learners the opportunity to select their own instructional transactions in terms of content, sequence, and the type of performance, in modes ranging from perusal to independent practice.
\end{abstract}

Formative evaluation is defined and a practical application, namely, learner-evaluation of students' interaction with this practice environment is described, based on questionnaires, interviews, and a post-test. Conventional evaluation is conducted of learner-attitudes and product effectiveness, but particular attention is paid to the five " $\mathrm{C}$ " characteristics introduced in the previous article: cognitive learning, constructivism, component-based instruction, customization and creativity. The Five $\mathrm{C}$ model has subsequently been extended to incorporate a sixth $\mathrm{C}$, collaborative learning, and has thus become the Hexa-C Metamodel. The practical evaluation of the practice environment is particularly focused on investigating the level of attainment of the characteristics embodied in the Hexa-C Metamodel.

\section{INTRODUCTION}

$\mathrm{T}$ his article is a follow-up to "Instructional theories of experts: a practical implementation", which appeared in SAJHE Volume 12(2) of 1998 (De
Villiers 1998). It reviews the theories introduced in that article, overviews literature on the evaluation of computer-aided instruction (CAI), and describes a tertiary-level student-evaluation conducted by the author on FRAMES, a computer-based interactive learning and practice environment in theoretical computer science. The main research methodologies used were questionnaires on the general usage of FRAMES in order to evaluate learner-attitudes and product effectiveness, as well as questionnaires and interviews centred on aspects related to the Five C's identified in the previous article, namely: cognitive learning, constructivism, component-based instruction, customization and creativity. The Five $\mathrm{C}$ model has subsequently been revised and expanded to incorporate a sixth $\mathrm{C}$, collaborative learning, and has become the Hexa-C Metamodel (De Villiers 1999a). The evaluation primarily investigates FRAMES to test conformance to the theoretical and practical characteristics embodied in the Hexa-C Metamodel.

Classical instructional design (ID) aims to apply optimal methods to promote knowledge acquisition and skills in learners. It proposes models and methodologies for systematic design and development of instructional materials, aiming to make instruction more effective, efficient and relevant. Objectives, content, instructional methods, and evaluation procedures of instructional materials should be consistent with each other. Upon a foundation of learning and instructional theories, instructional design proposes characteristics of educational practice, instructional products, and their development processes. The principles also apply to computer-based instructional products, and FRAMES was built in the ethos proposed by Mehl (1993:13): "The successful application of the computer in education is directly dependent upon instructional design ingenuity backed by a solid foundation in learning theory and learner research."

Evaluation of instructional materials should therefore determine not only their effectiveness and relevance, 
but also whether the underlying theories are successfully applied. Formative evaluation (Weston et al 1995: Weston et al 1997) is defined as evaluation during product development, ie iterative tryouts, for the purpose of improvement. It was first applied to text materials but is now widely accepted in the development of varied instructional media, such as audiovisual, interactive TV and CAI. Reigeluth (1996) describes current instructional design as a systematic process aimed at creating instruction that is effective, efficient and appealing. To achieve this, authors must accept the need for focused change. The key idea of formative evaluation is adaptation prior to adoption, ie incorporation of evaluation feedback into the revised materials. Various stakeholder groups should be involved, such as subject matter experts, experts on the target population, as well as learners. Research on formative evaluation has generally focused on effectiveness, defined in terms of learner-achievement (Weston et a/ 1997). Later studies related to methods of gathering feedback and sources of feedback. The main purposes of formative evaluation are rectification, revision, and improvement.

There are certain empirical methods (Weston et al 1995) that comprise a formative evaluation, namely. the procedures, techniques, and instruments used. Procedures include the steps taken in planning the evaluation, such as selecting participants and their roles, and deciding on techniques and instruments. Techniques are loosely-structured heuristic tools such as expert walkthrough, observation and interviews, while instruments are highly-structured tools such as questionnaires and specific algorithmic means, such as formal tests. The final component of an evaluation entails more personal situations, such as one-to-one report-backs, collaborative discussions, or one-togroup sessions like focus-group interviews.

\section{GOAL, TARGET GROUP, AND DOMAIN OF FRAMES}

The author designed an instructional software package for an interactive learning and practice environment called FRAMES. Its target group is first-level Unisa students, taking the module COS101 S, Theoretical Computer Science 1, by distance education. The content relates to infinite relations, a difficult section within discrete mathematics. Readers are referred to the author's previous SAJHE article (De Villiers 1998); certain aspects are, however, repeated.

The goal of FRAMES is to use ID principles to produce a practice-environment, an "androgogic activity box" providing various instructional activities and feedback on learners' efforts. Its human-compu- ter interface is a "virtual table-top", providing the objects (diagrams, definitions, worked examples, etc) that would lie on students' desks during typical problem-solving sessions.

FRAMES assumes subject-matter grounding, and was designed to offer extensive and intensive practice opportunities in sub-skills and composite problemsolving skills, to present visual aids, to offer help, and to increase general domain-familiarity, all within the context of specific examples. It was built (De Villiers 1995, 1996; Kotze \& De Villiers 1997), using the authoring language TenCORE 5.0. This highly interactive environment entails innovative instructional strategies, and called for programming techniques new to Unisa. The requirements were imprecise, requiring testing and evaluation. Screen layouts evolved in a form-follows-function manner, rather than adhering to specifications or storyboards. Prototyping was the ideal development route, since it is conducive to modification of the approach and strategies.

In CAl terminology a FRAME refers to a screen presentation. The central acronym, RAM, within

"FRAMES" is significant, because learners select by RAM control. Using on-screen control, they make three decisions when choosing a component "to view or to do":

1. Which Relation to choose: On selection of one, its definition component appears on-screen as a "blackboard". The Relations form the set: $\{\mathbf{P}, \mathbf{Q}$, S, T, V, W, TR \} where, eg:

- $\mathbf{P}$ is the set on $\mathbf{Z}$ of all $(\mathbf{x}, \mathbf{y})$ pairs such that $\mathbf{x} \leq$ $\mathbf{y}$ (the domain $Z$ is the set of integers, $\{\ldots,-2$, $1,0,1,2, \ldots\})$

- $\mathbf{Q}$ is the set on $\mathbf{Z}$ of all $(\mathbf{x}, \mathbf{y})$ pairs such that $\mathbf{x}-$ $\mathbf{y}=\mathbf{3 k}$ ie the difference between $\mathrm{x}$ and $\mathrm{y}$ is a multiple of 3 .

- $S$ is the set on $P$ of all $(\mathbf{x}, \mathbf{y})$ pairs such that $\mathbf{x} \mid \mathbf{y}$ ie $x$ is a factor of $y$, and $y$ is a multiple of $x$ (the domain $\mathrm{P}$ is the set of positive integers, $\{1,2$, $3, \ldots\})$.

2. Which Attribute of that relation to view, apply, or test the attributes being:

\section{\{Examples, Graphic, Property, Kind\}:}

- Example requires the learner to synthesize members of the current relation.

- The Graphic attribute shows a visual representation.

- Property attributes present mathematical proofs of: \{reflexivity, irreflexivity, symmetry, antisymmetry, transitivity, trichotomy\}.

- The special Kinds of Relations, \{equiva- 
lence, weak-partial-order, weak-total-order, strict-partial-order, strict-total-order\}, allow learners to view model analyses, or do independent testing to determine whether the appropriate criteria are satisfied. FRAMES selects the relevant set of property tests for the composite "Kind" analyses from its knowledge base, and checks students' input in the independent mode.

3. The choice between Modes $\{\mathbf{1}, \mathbf{2}, \mathbf{3}\}$ for doing property and kind exercises:

- Mode 1 demonstrates a read-only proof constructed step-by-step.

- Mode 2 offers guided practice using fill-inthe-blank structures.

- Mode 3 encourages independence, interspersing linking-structure with blank lines on which learners input a do-it-yourself (DIY) proof.

These modes cover the same content in different ways. Modes 2 and 3 operate by keyboard-input and by mouse-clicking to select mathematical characters from a symbol pad. They also incorporate judgement. present feedback, and accept correct alternatives.

\section{THE GENERAL EVALUATION}

Evaluations were conducted in the Unisa context of distance education (De Villiers 1999b), with limited learner-accessibility. Empirical studies were carried out, the main research methodologies being questionnaires in 1997 and in-depth interviews in 1998.

A general tutorial letter sent to all students registered for the module in 1997 included a call-for-volunteers. This resulted in a sample of eighteen participants, representing a broad spectrum of the heterogeneous students. They used the FRAMES environment and completed the questionnaire in their study situations at home, at work, or in Unisa computer laboratories. Three discontinued the module, but of the remaining fifteen, fourteen completed questionnaires. The questionnaire commences with an unstructured, openended section for students' own comments, which they were required to complete prior to reading the questionnaire, so as to express spontaneous impressions. This was followed by a section of highly structured questions with graded scores, incorporating spaces for open-ended comments. Certain concepts were investigated more than once, in different places and using different terminology, to obtain confirmation of learner-reaction. There were openended elaboration options, such as: "If you answered
'YES', why?". Students were invited to express frustrations, to describe how FRAMES helped, and to state what they found the most useful/difficult, etc. Triangulation, the use of data from multiple sources, was applied, in that the researcher held informal telephonic or personal interviews with about half the respondents, and investigated subsequent examination marks as a post-test.

A follow-up study in 1998 entailed in-depth, structured interviews with a few students; these focused on assessing the effectiveness of the application of learning and instructional theories. Four participants (including two disadvantaged learners) responded to a call-for-volunteers in the Pretoria region (immediate locality only, so as to facilitate interviews). Three were seen personally and one was interviewed by telephone. The enthusiastic and whole-hearted participation of these four students is greatly appreciated.

\section{Structured questions in the questionnaire}

These related to:

- use and functionality of the demo screens,

- ease or complexity of operation, navigation and accessibility,

- general perception, ie enjoyment, or otherwise, of doing exercises using FRAMES,

- degree of use of the components such as help. definitions, elaborations, synthesis of examples, graphic aids, etc

- attitudes to learner-control,

- utility and perception of the three modes,

- the feedback,

- aesthetics of screens and degree of screen-load,

- sources of frustration,

- use of FRAMES at different stages in studies, and

- the absence of scoring.

Answers were rated on the following five-point scale:

\begin{tabular}{|c|c|c|c|c|}
\hline $\begin{array}{c}5 \\
\text { Strongly } \\
\text { agree }\end{array}$ & $\begin{array}{c}4 \\
\text { Agree }\end{array}$ & $\begin{array}{c}3 \\
\text { Maybe }\end{array}$ & $\begin{array}{c}2 \\
\text { Disagree }\end{array}$ & $\begin{array}{c}1 \\
\text { Strongly } \\
\text { disagree }\end{array}$ \\
\hline
\end{tabular}

The averages, shown in Table 1, indicate generally positive learner-perceptions. The standard deviations measure the variability of a set of data. Low values show that responses to a question are clustered. whereas greater values indicate more dispersion. The situations with greater variations show how students' perceptions of and usage of FRAMES vary from individual to individual, which was a direct intention in designing the environment. 
Table 1

Responses to structured questions

\begin{tabular}{|c|c|c|c|}
\hline & Statement & Average & Standard \\
\hline 1 & The demo screens are easy to use & 4.28 & 0.61 \\
\hline 2 & $\begin{array}{l}\text { The demo screens helped me get started, so I knew what to do when I started } \\
\text { the RAM exercises. }\end{array}$ & 4.07 & 0.73 \\
\hline 3 & When I do RAM exercises, I can easily access the one I want. & 4.43 & 0.65 \\
\hline 4 & I like practicing on the computer. & 4.43 & 0.87 \\
\hline 5 & The FRAMES system is easy to operate. & 4.07 & 0.62 \\
\hline 6 & The blackboard-style definition of the current relation at top left is helpful. & 4.43 & 0.19 \\
\hline 7 & The step-by-step build-up of answers really helps. & 4.71 & 0.21 \\
\hline 8 & $\begin{array}{l}\text { It is easy to access the HELP information such as definitions and graphic } \\
\text { aids. }\end{array}$ & 4.57 & 0.45 \\
\hline 9 & The definitions of mathematical properties are a useful form of HELP. & 4.64 & 0.5 \\
\hline 10 & $\begin{array}{l}\text { The attribute called "EG" (for synthesis of ordered pairs) helps me to } \\
\text { understand the relation. }\end{array}$ & 3.86 & 0.67 \\
\hline 11 & The graphic aids help me get a feel on the relation. & 4.07 & 0.62 \\
\hline 13 & FRAMES is complicated to use. & 2.07 & 0.83 \\
\hline 14 & $\begin{array}{l}\text { It is easy to understand the meaning of the icons and symbols in the right- } \\
\text { hand quick-control column. }\end{array}$ & 4.07 & 0.62 \\
\hline 15 & I got stuck. & 2.07 & 0.83 \\
\hline 16 & $\begin{array}{l}\text { I appreciate the learner-control that lets me do what I want, as much as I } \\
\text { want and in the way of my choice. }\end{array}$ & 4.36 & 0.84 \\
\hline 17 & The feedback was useful. & 3.5 & 1.02 \\
\hline 18 & I learned to use FRAMES quickly. & 4.5 & 0.52 \\
\hline 19 & There is too much information on the screens. & 2.29 & 0.83 \\
\hline 22 & I find the process lengthy and laborious. & 2.21 & 0.89 \\
\hline 24 & I prefer doing excercises on paper. & 2.86 & 1.35 \\
\hline 25 & I find it difficult to use the RAM access method & 1.64 & 0.91 \\
\hline 26 & It was useful having the structure of the proof set out in Mode 2 and Mode 3. & 4.14 & 0.73 \\
\hline 27 & $\begin{array}{l}\text { It is difficult using both the mouse and the keyboard to enter answers in } \\
\text { Modes } 2 \text { and } 3 \text {. }\end{array}$ & 2.79 & 1.48 \\
\hline 28 & $\begin{array}{l}\text { After using the pre-set structures in FRAMES, I will know how to approach } \\
\text { written examples in the exams. }\end{array}$ & 3.57 & 0.94 \\
\hline 29 & $\begin{array}{l}\text { It is a waste of time doing interactive practice when I can read worked } \\
\text { examples in the tutorial material. }\end{array}$ & 1.29 & 0.47 \\
\hline 30 & $\begin{array}{l}\text { FRAMES helped me with the more complex proofs in the section of } \\
\text { COS101 S on relations. }\end{array}$ & 4.21 & 0.58 \\
\hline 31 & I would use FRAMES in different ways at different stages in my studies. & 3.86 & 0.86 \\
\hline 32 & $\begin{array}{l}\text { I know that FRAMES is intended to be a non-threatening practice } \\
\text { environment, nevertheless I would like a scoring facility. }\end{array}$ & 3.21 & 1.42 \\
\hline 33 & I should like practice environments for other sections of my studies. & 4.71 & 0.61 \\
\hline
\end{tabular}




\section{Questions relating to the modes of use}

The study of the modes, shown in Table 2, proved most valuable. The response to question 21 shows that equal numbers of students selected each of modes 1,2 and 3 respectively as the one from which they learned most, which demonstrates the value of FRAMES in individualization. Students found Mode 1 straightforward and non-stress-producing, good for first overviews and quick revision. Mode 2 taught them to be methodical and to grasp the structure of mathematical proof processes: "it made me think" / "really guides me". The help, hints, and interrelationship between theory and practice provided in this mode, were appreciated. One student requested optional short cuts omitting the fillingin of definitions, useful initially, but cumbersome later. Mode 3 (question 23 and comments). although considered difficult, demanding, and time-consuming, contributed to ultimate retention of the material and methods: "helps me to remember" / "ideal for exam practice".

\section{Responses to open-ended and unstructured questions}

Of the fourteen students who completed the questionnaire, twelve were very positive. One was consistently critical and another expressed major reservations in addition to qualified praise. The open-ended responses were phrased in students own words. Some of these spontaneous comments are incorporated in the subsequent section on the evaluation of FRAMES with respect to learning and instructional theories. Others are classified and consolidated below:

\section{Positive comments}

No of students

User-friendly/good user interface/ fresh approach to interface

Good aesthetics/colour/screen layout

Very useful/helpful with difficult work

Helps me understand/explains well/ shows my mistakes

Enjoy it/love it!

8

Excellent practice/chance to test my abilities

Unfamiliar with computers but it was easy to use

6

Definitions very useful/well done

It really helped to synthesize examples

Explanations of maths symbols most useful

Not threatening/doesn't make me feel stupid

Wish I'd had it early in the year

\section{Negative comments}

No of students

Would appreciate a quick exit facility while doing exercises

Didn't appreciate the long introduction sequence

Would like to go back to demo from menu

Frustrated by pressing < Enter >

Screen overloaded

5
6
3
3
2

Table 2

Use of the three modes

\begin{tabular}{|l|c|c|c|}
\hline \multicolumn{1}{|c|}{ Statement } & $\begin{array}{c}\text { Mode 1 } \\
\text { No of students }\end{array}$ & $\begin{array}{c}\text { Mode 2 } \\
\text { No of students }\end{array}$ & $\begin{array}{c}\text { Mode 3 } \\
\text { Nof students }\end{array}$ \\
\hline 20 Mode I enjoy the most & 6 & 7 & 1 \\
\hline 21 Mode that helps me learn the most & 4 & 4 & 4 \\
\hline $23 \quad$ Mode I like least & 2 & & 9 \\
\hline
\end{tabular}




\section{Negative comments:}

No of students

Should explain the abbreviations and icons in the instructions

Difficult to use mouse and keyboard together

Frustrated by filling in blanks

Unfriendly user-interface/would like standard Windows GUI

Pity it's designed for DOS/ran it under Windows anyway

Three students identified a mathematical error, and one a spelling mistake; these have been corrected.

\section{Computer use}

The students were first-level and inexperienced with computers. Some felt threatened:

"I thought it would be overwhelming and I'd get lost, but I soon got used to it" / "it seemed daunting, but I soon felt comfortable".

\section{Typical practice sessions}

Some students started by testing for one specific property investigating that property on different relations, then moving on to analyse the overall kind of each relation. Others appreciated the value of synthesizing examples, to get the feeling of a relation, before doing guided practice with mode 2. Several worked in the traditional manner, first studying theory and definitions, then using mode 1 for initial learning before moving on to proofs in mode 2 for consolidation and mode 3 as their knowledge increased. The explanations of maths symbols, available on demand, were found most useful.

\section{Visualization}

A strong weighting in response to question 11 on the FRAMES graphics, and six positive open-ended responses, demonstrated the value of visualisation by means of the graphic aids.

\section{Judgement and feedback}

Designing, and in particular programming, feedback was one of the most complex parts of FRAMES development! Students appreciated the diagnostic feedback and the "try again" opportunity, but would have liked it even more sensitive and extensive. Such an interactive area, bordering on the threshold of intelligent software, is a realm where the computer lags behind a human mentor. Despite the variety of equivalent and synonymous answers that FRAMES accepts as correct, students identified additional correct options not accepted by the embedded judgement procedures. Two students also requested a visual indication of exactly where they erred, and two others asked for more clues as to the nature of the error, or a comprehensive diagnosis of "exactly what I did wrong". Were these students tackling COS101 nearer the end of their Computer Science studies, they might have appreciated the intense intricacies of programming human-style judgement and feedback facilities!

A valid complaint is that proofs are accepted in a standard format only, with minor variations. FRAMES' judgement facilities do "not help if I use a completely different approach". A further problem is the re-entry of a whole line, instead of being able to correct mistakes by editing.

\section{Post-test}

Students' marks for the question on complex relations in the final examination were used as a post-test. The question counts 10 marks out of a total of 100 . The average mark obtained for this question by the fourteen students in the 1997 study was 5.6, whereas the general average was 4.7, ie the students in the experimental group performed $9 \%$ better. The results in the 1998 study were even better the four interview students obtained 9, 8, 7 , and 6 out of 10 respectively, against a general average of 4.4

\section{EVALUATION OF FRAMES WITH RELATION TO THE LEARNING AND INSTRUCTIONAL THEORIES OF THE HEXA-C METAMODEL}

De Villiers (1998) describes the so-called "Five C's" currently influencing ID. The model was subsequently extended to incorporate a sixth C, namely, cooperative learning, and was named the Hexa-C Metamodel (De Villiers 1999a; 1999b). This section discusses the evaluation of FRAMES from the viewpoint of conformance to current learning and instructional theories, as it investigates the level of attainment of each of the six characteristics. The 1998 interview evaluation was explicitly focused on these aspects, and the 1997 evaluation, implicitly. Responses in both studies demonstrate that FRAMES conforms to the objectives embodied in the Hexa-C Metamodel. Extracts from student-responses are incorporated.

\section{Cognitive learning}

Cognitive learning relates to the reasoning and 
thinking processes used by learners as they acquire knowledge and skills. Perception and learning are viewed as reorganization of the brain's knowledge structures, as learners construct meaning by integration of new with existing knowledge, using mental schemata (Inhelder \& Piaget 1958) to facilitate comprehension and to aid recall. Higher order thinking skills (HOTS) (Vockel \& Van Deusen 1989; Dunlap 1999) comprise metacognition (understanding one's own cognitive processes and learning strategies); critical and creative thinking; the skills of classification, analysis and synthesis; and consideration of topics from multiple perspectives. Learners who use HOTS think at a conceptual level rather than by rote memorization. Hannafin and Peck (1988) emphasize instructional design principles based on cognitive learning theory: instructional media should support orientation and recall of prior knowledge: intellectual skills and learning strategies should be fostered. Dunlap (1999) defines Rich Environments for Active Learning (REALs) which, among other features, support intentional learning by encouraging student-responsibility, -initiative, and-decision making; apply dynamic generative learning activities that promote HOTS and integrate new knowledge with old in order to create rich and complex knowledge structures; and reinforce reflection on the learning process itself, as well as on the subject-content Jonassen and Reeves (1996) states that welldesigned cognitive tools should engage learners in critical thinking; assist learners in the acquisition of generalisable skills; and be easy to learn and use.

It is important to include instructional and cognitive features in learning materials over and above the actual subject matter, in order to help learners actively plan their study experiences. FRAMES facilitates study by implicit and explicit incorporation of such aspects:

- Integration of new with prior knowledge: "I really appreciated the way definitions were built into the proofs" / "first used it to learn definitions, then practiced relationships" / "I learned how to define properties, then I could start proofs".

- Metacognition learners monitoring their problem-solving activities: "taught me to think analytically" / "to solve a problem it makes you think of all the things related to it".

- Schemata (representations to show relationships) and heuristics (rules) to help learners construct internal conceptual schemata: "The guidance in mode 2 explains it all" / "taught me to combine concepts".

- Chunking rational ordering, step-by-step, avoiding cognitive overload: "When you see only one part at a time, you realize what is most important".
- Rehearsal and multiple presentation, approaching and reviewing material from different perspectives: "For a specific relation, I would first do mode 1 then mode 2 then mode 3 ".

\section{Constructivism}

Constructivism is a branch of cognitive learning theory, based on learners actively constructing their own knowledge (Dick 1991). It is increasingly attractive in the public learning system, with its critical need to motivate and engage diverse learners, and is applicable for Unisa with its distributed and heterogeneous student-body. Constructivists object to pre-specified objectives and criterion-referenced testing, preferring contextualized learning environments where learners explore and set their own goals (Dick 1996). Nulden (1999) and Florea (1999) review the value of problem-based learning, an implementation of constructivistic learning, where the starting point of learning is presentation of a real-world situation or relevant problem, and the purpose is to encourage exploration, construction and active learning

Constructivism supports learner-involvement in product development. Hannafin et al (1997) discusses grounded-constructivist learning environments, which emphasize learning rather than instruction. Grounded designs are based on systematic implementation of processes and procedures rooted in human learning theories, and are related to case studies of validated strategies and empirically tested research, involving iterative user-evaluation of instructional systems. Feedback from user-evaluations should be incorporated into the revised versions. The theoretical framework itself can be refined as the system under assessment is shown to clarify or extend the theoretical basis.

In discussing the long-term impact of vocational training models, Dick (1996) highlights the need for real-world performance and on-the-job progress, rather than post-test achievement. A means towards achieving such goals is the total quality management (TQM) approach which emphasizes the importance of the perceptions of both clients and learners in the determination of quality. Clients should be involved in needs assessment, in design, and in determining when products meet expectations. Learners should do formative evaluations, assessing products in the workplace, which is an extension to Dick's traditional model of instructional design.

The user-evaluation of FRAMES evidenced a constructivistic and problem-based bias: 
- Active participation learners planning and controlling their own learning and practice experience: "When you listen to a taught lesson or watch a video, you remember the beginning and the end. but when you are involved in doing it, you can't forget" / "the best part is that you must interact".

- Anchored instruction and contextualized process development: "It's brilliant to see the patterns in mode 2" / "after doing proofs I know what the theory means when I open the book again", ie using examples to progress to the underlying theory.

- Visualization / graphic aids perception by illustrations: "another way to get it into my head" / "diagrams make the concept clearer" / "they really help me understand the relations" / "written definitions can be so cumbersome" / "these aids make it simpler for me".

- Real-world relationships by example synthesis: "They give me ideas, so I can work out what the right answer will be" / "it helps me see which pairs really belong in the relation".

- Transfer applying the strategies to more complex problems: "When I do different problems, I know how to apply it".

- Integrated testing, ie no formal testing or scoring that might threaten or raise unwarranted optimism: "It never made me feel stupid", on the other hand: "I would like a mark, not every time, but when I feel ready".

\section{Customization}

Reigeluth (1996) states that the design paradigm of instructional materials must change to meet the information age. A "learning-focused" paradigm requires customization to individual learners, rather than standardization; and entails the facilitation of learning, rather than mere presentation of material. Instruction should include personalised knowledge construction, leading to true learning. Instructional materials should offer flexible guidelines so that learners take the initiative, choosing between diverse methods, using technologies (possibly in teams), and persevering individually, within their own timeframes, to reach appropriate standards. Learners should develop problem-solving skills, which can be applied in complex domains. Hannafin and Peck (Hannafin 1988) state that individualization should be implemented by adapting to each learner's profile and needs; learning time must be flexible; and attention should be paid to affective considerations to encourage positive learner-attitudes. Gilbert and Han (1999) mention various learning styles, for example, audio, visual, and textual preferences.
The evaluation showed FRAMES to be strong on customization and individualization. The responses, discussed earlier, relating to modes and practice sessions, demonstrate the variety of ways in which FRAMES is used. It is not an artificial intelligence system, but is characterized by adaptability, individualization and high interactivity, meeting individual learner's needs by customization in terms of material tackled, help facilities used, and systems responses. To distance learners, unaccustomed to individual attention, it offers personalized support by:

- User-control for efficient learning, as students select components appropriate to their learning style and stage of study: "I could choose what to do!" / "I'm very systematic, so I did every one. I tried out everything, even different answers, to see if they were also right".

- Feedback geared to likely errors, with several versions available at each answer-entry point. Response-judging is a major processing event in FRAMES, as learners' input is assessed. Provision is made for two attempts at each answer-entry point; alternative correct answers and spelling variations are acceptable: "When I get an answer from the computer, then I remember it".

- Multiple presentation of information: the utility of each of the three modes was confirmed. Each was, for an equal number of students, the one from which they learned most. Others appreciated a certain mode at a particular stage of study. FRAMES thus supports differing learning styles, and also the different needs of the same learner at different times. A third aspect is the modes' complementary nature, in that a judicious combination results in true learning, consolidation, and skill acquisition, rather than mere knowledge assimilation.

- Explanations and help facilities: "They helped me for maths symbols that I'm not familiar with" / "I didn't need them I know them all".

- Varied type and quantity of practice sub-skills or composite skills; as many as required.

\section{Creativity}

Instruction can be dull, prescriptive and formal (Dick 1995). Programmed instruction models originated from Skinnerian psychology, and despite the inclusion of objectives, criterion-referenced testing, and Gagné's classical events of instruction and conditions of learning (Gagné 1985), instructional materials frequently bore learners. However the current keywords are creativity and novelty! Many state-of-theart instructional packages are characterized by innovation and learner-engagement. The conventional 
evaluation criteria of effectiveness and efficiency are being supplemented by those of creativity and engagement. It should be determined (Weston et al 1995) whether instructional materials are appealing and hold learners' attention, and whether learners find them attractive, likeable, interesting or merely acceptable. Instructional designers should be open to new paradigms. Taking an "eclectic and pragmatic view of learning, with a bias towards constructivism", Cumming et al (1999) propose a balance between freedom and structure; between challenging learners, yet simultaneously supporting them. They suggest the term, Educational Design (in place of Instructional Design) to represent a paradigm of "activity sets" presented to learners in a variety of formats, including worked examples, demonstrations, simulations exercises, exposition and more.

Tertiary and adult education have been viewed as serious occupations, tackled voluntarily; little effort is made to engage students and make their studies pleasurable. However, instructional designers in vocational training and business settings (Caropreso \& Couch 1996) are also becoming aware of the value of creativity, novelty and innovation in their products. In an example of this paradigm-shift at tertiary level, Basson and Cilliers (1997) state that although physicists view their discipline as an art, the average student finds it difficult and tedious. The Unisa Physics Department, accepting the value of experimentation, set out to improve their students' learning experiences by creating and evaluating an innovative student-centered model for first-level practical work. Students were sent an experimental kit, comprising every-day items, for doing home experiments. In the evaluation, 50\% of the students were positive, and described their assignment as "fun", "innovative" and "a joy".

The FRAMES evaluations indicate that students found it attractive and appealing:

- Matching learners' specific interests (Dick 1995) Computer Science students appreciated CAI: "When I work on computer I never think about time" / "the computer draws me it's a better way" / "I never knew you could do educational things on the computer it's amazing!".

- Motivational strategies, Keller's (1987) ARCS model entailing:

gaining and holding attention: "I find it entertaining could do it all day!" / "It was easy, I never got cross with it" / "the nicest way I've ever learned" / "loved it" / "could not get off the computer" / "absolutely brilliant" / "absoluut wonderlik", and best of all, "excellent I even forgot I was learning":

demonstrating relevance: "shows all the important things, so you don't waste time" / "good for Unisa students, because it tells you immediately, you don't wait for the next day to phone a lecturer";

instilling confidence: "Now I know why to do things that way" / "I'm positively clear about things I used to think were difficult" / "now | can go it alone!";

providing learner-satisfaction as they organize their own learning experiences, tackle varied activities in the spirit of Cumming et al's educational design (1999), and gain self-confidence when performance improves: "Typing examples was the best way to see if you understand" / "If you get it wrong you must think why".

- High interactivity produces intrinsic motivation: "After a session I feel I must sit down and master the next section. I want to work more".

- FRAMES' virtual table top concept the screen layout and user interface offer the objects commonly found on students' tables: "Everything was there, I never needed the book" / "You must read the book first, then you can put it away, because you have all you need" / "FRAMES gives the main concepts concisely".

\section{Component-based structure and transaction theory}

Component Display Theory (CDT) (Merrill 1983, Merril et al 1996) is based on Gagné's conditions of learning and the assumption that varying instructional strategies are required to achieve different instructional objectives. It proposes relationships between the type of performance required and the type of content to be taught. Merrill's performance categories are: remember, use, and find, forming the basis of Mode 1 (read-only perusal), Mode 2 (guided practice, applying the principles) and Mode 3 (DIY skill practice) respectively. The content categories are: fact, concept, procedure and principle, relating to knowledge ranging from the most basic units through to the applied and analytical. Materials developed according to CDT principles accommodate personal learning styles and needs. Learner-control allows learners to choose instructional components from a set of options, encouraging active cognitive processing by providing environments in which they select both the instructional strategy and the content. 
FRAMES has a component-based structure, with no fixed combinations of on-screen units. Components are used simultaneously, so that screens present a windowed appearance. The evaluation showed how students selected instructional transactions, choosing their own personal set of components, both in terms of content and instructional strategy (ie mode). They decide on the sequence and quantity of practice, choosing the modes / definitions / elaborations / examples / illustrations / proofexecutions appropriate to their individual learning style or stage.

- Performance components: "I first use mode 1 to understand" / "Mode 1 shows you how to do it, then the others prove whether you can. You move on to them because the person behind the computer has shown you how to do it" / "I read mode 1 step-by-step, guessing what comes next" / "For exams you practice with mode 3" / "I use those difficult kind-of-relations to get confidence before the exam".

- Combinations of components: "You keep one on the screen to use as a model. Then you do a different one using the pattern".

- Content components used in different ways: "I liked that you could take one relation and do so many different tests" / "I first use examples (synthesis of members of the relation) to see how it really looks" / "I choose one relation, starting with its properties then do it all together, analysing the kind" / "I take one property, eg reflexivity, and do it on each relation".

\section{Collaborative learning}

Collaborative learning emphasizes participative and flexible communication, teamwork, peer-evaluation, and extensive learner-input. Johnson and Johnson (1991) propose collaborative learning as a means of learning alone and together with a mutual goal, positive inter-dependence, and individual accountability. The concept of positive goal interdependence entails a team approach in which learners need input from others in order to complete tasks, yet remain personally responsible and accountable. Collaboration is an important aid in learning problem-solving strategies, especially in extensive, complex domains. Many current computer-based applications are specifically designed to encourage collaborative learning (Gordon \& Hall 1999).

The FRAMES environment is not a virtual classroom and makes no provision for authentic computersupported collaborative learning or for learnerlearner-instructor communication. It was designed as a stand-alone system for isolated distance learners, yet several participants spontaneously chose to work two-at-a-computer, and described this collaborative use. They found that co-operative problem-solving led to enrichment and better performance:

- Discussion and debate: "We have different ideas and they collide, then we go together to the computer and it explains" / "It really helped now I want to show my friend on the computer!".

- Interdependence and improved performance: "At the beginning he understood more and he helped me. But now I can do it better!"

\section{CONCLUSION}

The interactive learning and practice environment, FRAMES, was evaluated by Unisa students. Functioning of the user-controlled, component-based system was as the author had envisaged, yet even richer, as some students found unanticipated applications. FRAMES was also evaluated to test its conformance to the principles of the Hexa-C Metamodel, the six C's being various stances currently advocated by instructional experts, namely: cognitive learning, constructivism, customization, creativity, component theory, and collaborative learning. It was found to support them strongly.

FRAMES has been empirically demonstrated to be a rich learning environment, supporting the current paradigm shift towards flexible instructional software. Its high levels of interactivity and individualization capitalize on the capabilities of the computer, customizing the environment to the needs of individual learners. Students were engaged by its innovative. cognitive strategies, and were delighted to have total control of their learning experiences, supported by a comprehensive virtual table-top. Interactive practice (sometimes in small groups), accompanied by instant feedback, enriched their studies and led to retention of content. Let learners, themselves, conclude this article...

"As a distance education student, I can't ask questions, but with FRAMES I can";

"The part of my studies I enjoyed most";

"I could try things out the things I wonder about ... and I learned so much". 


\section{REFERENCES}

Basson, I \& Cilliers, J A 1997. At last ... Physics is fun! Progressio 19 (1):106 129, Unisa.

Caropreso, EJ \& Couch, R A 1996. Creativity and innovation in instructional design and development. Educational Technology 36(6):31 39.

Cumming, G, Finch, S \& Thomasen, N 1999. Educational design for effective learning. Advanced research in computers and communications in education. Proceedings of ICCE '99. $7^{\text {th }}$ International Conference on Computers in Education. Ohmsha: IOS Press.

De Villiers, M R 1995. Integrating a software engineering approach and instructional factors in instructional software development, illustrated by a prototype in theoretical computer science. MSc thesis, University of South Africa, Pretoria.

De Villiers, M R 1996. A component-based interactive practice environment, in Proceedings of 3rd International Conference on computer aided learning and instruction in science and engineering. Spain: San Sebastian.

De Villiers, M R 1998. Instructional theories of experts: a practical implementation. South African Journal of Higher Education 12(2):204 214.

De Villiers, M R 1999a. Applying the Hexa-C Metamodel of instructional theory and design to educational Web applications, in Proceedings of WebNet99 World Conference on the WWW and Internet. Charlottesville, VA: AACE

De Villiers, M R 1999b. Evaluation of an interactive learning environment using the Hexa-C Metamodel, in Advanced Research in Computers and Communications in Education, Proceedings of ICCE '99. $7^{\text {th }}$ International Conference on Computers in Education. Ohmsha: IOS Press.

Dick, W 1991. An instructional designer's view of construction. Educational Technology 31 (5) 4144.

Dick, W 1995. Instructional design and creativity: a response to the critics. Educational Technology 35(4):5 11.

Dick, W 1996. The Dick and Carey model: will it survive the decade? Educational Technology Research and Development 44(3):55 63

Dunlap, J C 1999. Rich environments for active learning on the web: guidelines and examples, in Proceedings of WebNet99 World Conference on the WWW and Internet. Charlottesville, VA: AACE.

Florea, A M 1999. An agent-based collaborative learning system, in Advanced Research in Computers and Communications in Education. Proceedings of ICCE '99. $7^{\text {th }}$ International Conference on Computers in Education. Ohmsha: IOS Press.

Gagné, R M 1985. The conditions of learning. New York: Holt, Rinehart and Weston.

Gilbert, J E \& Han, C Y 1999. ARTHUR: Adapting Instruction to Accommodate Learning Style, in Proceedings of WebNet99 World Conference on the WWW and Internet. Charlottesville, VA: AACE

Gordon, A \& Hall, L 1999. Facilitating collaborative learning in virtual environments, in Advanced Research in Computers and Communications in Education, Proceedings of ICCE '99. $7^{\text {th }}$ International Conference on Computers in Education. Ohmsha: IOS Press.

Hannafin, M J \& Peck, K L 1988. The design, development, and evaluation of instructional software. New York: MacMillan.

Hannafin, M J, Hannafin, K M, Land, S M \& Oliver, K 1997. Grounded practice and the design of constructivist learning environments. Educational Technology Research and Development 45(3):101 117

Inhelder, B \& Piaget, J 1958. The growth of logical thinking from childhood to adolescence. New York: Basic Books Inc.

Johnson, D W \& Johnson, R T 1991. Learning together and alone. Englewood Cliffs, NJ: Prentice Hall.

Jonassen, D H \& Reeves, T 1996. Learning with technology: using computers as cognitive tools, in Jonassen, $\mathrm{D} \mathrm{H}$ (ed) Handbook of research for educational communications and technology. New York: Macmillan.

Keller, J M 1987. Strategies for stimulating the motivation to learn. Performance and Instruction 26(8):1 7.

Kotze, P \& De Villiers, M R 1997. Applying software engineering methods to instructional systems development. South African Computer Journal 20 (December):49 56.

Mehl, M C \& Sinclair, A J L 1993. Defining a context for CAl: in quest of educational reality, in Lippert, R C (ed) Computer based education and training in South Africa. Pretoria: J L van Schaik Publishers.

Merrill, M D 1983. Component display theory, in Reigeluth, C M (ed) Instructional design theories and models: an overview of their current status. Hillsdale, N.J.: Lawrence Erlbaum Associates.

Merrill, M D, Drake, L, Lacy, M J, Pratt, J \& ID 2 Research Group 1996. Reclaiming instructional design. Educational Technology 36(5):5 7.

Nulden, U 1999. PIE Problem Based Learning, interactive multimedia and experiential learning, in Proceedings of WebNet99 World Conference on the WWW and Internet. Charlottesville, VA: AACE.

Reigeluth, C M 1996. A new paradigm of ISD. Educational Technology 36(3):13 20. 
Vockell, E \& Van Deusen, R M 1989. The computer and higher order thinking skills. Watsonville, CA: Mitchell Publishing Inc. Charlottesville, VA: AACE.

Weston, C, McAlpine, L \& Bordonaro, T 1995. A model for understanding formative evaluation. Educational Technology Research and Development 43(3):29 48.

Weston, C, Le Maistre, C, McAlpine, L \& Bordonaro, T 1997. The influence of participants in formative evaluation on the improvement of learning from written instructional materials. Instructional Science 25:369 386. 